\title{
Growth and Characterization of an Organic Nonlinear Optical Crystal:
}

\author{
1-lodo-3-Nitrobenzene (INB) \\ S.Vijayakumar ${ }^{1}$, P.Srinivasan ${ }^{2}$, S.Dinagaran $^{3}$, J.Balaji $^{4}$ \\ ${ }^{1}$ Department of Physics, Government College of Engineering, Dharmapuri-636704, Tamilnadu,India. \\ srinisir.vijay@gmail.com, \\ ${ }^{2}, 4$ Department of Physics, University College of Engineering Panruti-607 106,Tamil Nadu, India. \\ sril35@gmail.com,ramjbalaj@gmail.com, \\ ${ }^{3}$ Department of Physics, University College of Engineering - Thirukkuvalai-610 204, Tamil Nadu, India \\ sugadinagokul@yahoo.co.in, \\ *corresponding author and mail respond to srinisir.vijay@gmail.com
}

\begin{abstract}
The 1-lodo-3-Nitrobenzene crystal was grown by the slow evaporation method from ethanol solvent. The crystalline structure was identified by powder X-ray diffraction (PXRD). The presence of various functional group of the title material was examined by FTIR analysis. The UV-Vis absorption was carried out which shows the fundamental cutoff wavelength around $390 \mathrm{~nm}$ and there is no absorption in the entire visible region $390 \mathrm{~nm}$ to $1100 \mathrm{~nm}$. The mechanical strength of the grown crystal was measured by Vicker's microhardness tester. The thermal toughness of the grown crystal was observed by TGA-DTA and DSC studies. The electrical conductivity of the grown crystal is confirmed by dielectric measurement. The nonlinear optical character was assessed by Kurtz-Perry powder technique. This would propose that 1-iodo-3-nitro benzene crystal is a potentially capable in nonlinear optical applications.
\end{abstract}

Keywords: Organic crystal, Slow evaporation, Powder-X-ray diffraction, Nonlinear optics

\section{INTRODUCTION}

Recent past, the researchershave very much attraction to the design and growth of new materials in crystal form for scientific development in the core disciplines of physics, chemistry, biology and pharmaceuticals. Organic molecules in condensed solid state form molecular crystals which differ considerably in their mechanical, optical, electronic properties from some traditional solid state objects as covalent or ionic crystals. This is due to weak intermolecular interaction forces of the Vander walls type with binding energy considerably lower than that of covalent and ionic bonds in atomic crystals. Lattice energy is accordinglyvery low in molecular crystals which have low melting, sublimation temperature, low mechanical strength and high compressibility [1]. Nonlinear optics (NLO) is a field of study concerned with the interaction of light as electromagnetic radiation and matter in which the matter responds to the incident fields. The nonlinear character can result in intensity-dependent variation of the propagation characteristic of the radiation fields or in the formation of radiation fields that propagate at new wavelengths or in new directions. Over past three eras organic molecules have been the topic of many investigations for application in nonlinear optics. The merits offered by organic nonlinear optical crystals over inorganic nonlinear optical crystals include high electronic susceptibility through high molecular hyperpolarizabilty which involves some device applications such as second harmonic generators, electro-optic modulators, frequency converters, etc.[2-3].

1-iodo-3-nitrobenzene $\left(\mathrm{IC}_{6} \mathrm{H}_{4} \mathrm{NO}_{2}\right)$ is an organic nonlinear optical material. This crystal is grown from slow evaporation solution growth method by ethanol solvent. INB crystallizes in the non-centro symmetric, monoclinic space group $\mathrm{P} 1211$, the lattice parameters are reported as $\mathrm{a}=5,977 \AA, b=5.224 \AA, c=11.972 \AA$ [4]. 1-iodo-3-nitrobenzene is a particularly promising NLO material; in this article we report the growth and characterization of the title material.

\section{EXPERIMENTAL PROCEDURES}

\subsection{Crystal Growth}

1-iodo-3-nitrobenzene polycrystalline powder was purchased from Sigma-Aldrich Company. The solubility studies in different solvents showed that the solute is insoluble in water and highly soluble in ethanol. Hence the grown crystal was purified by repeated recrystallization process in ethanol.INBcrystals were grown by slow evaporation solution growth technique. Saturated solution of the solute with ethanol as a solvent was prepared and the temperature of the solution has been increased while stirring the solution in order to increase homogeneity of the solution. The solution was cleaned to remove any impurities present by grade one Whattman filter paper. Successively, to ensure the slow evaporation the beaker was protectedwith holed polythene paper and was preserved without interruption at dust free atmosphere.Optically clear yellowish single crystal has been grown in a span of 10 days at room temperature. The molecular structure and grown crystal are shown in figure 1. 
<smiles>O=[N+]([O-])c1cccc(I)c1</smiles>

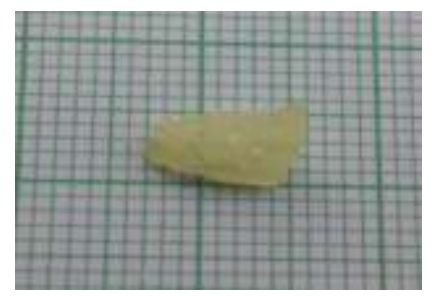

Fig 1: Molecular structure and grown crystal of INB

\subsection{Characterization Studies}

The grown crystal has been analyzed by various analysis techniques in order to check its aptness for device production. Powder X-ray diffraction analysis has been carried out for the grown crystal of 1-iodo 3-nitrobenzene (INB). The existence of functional groups has been identified from the Fourier transform infra-red spectral analysis (FT-IR) and its optical excellence has been analyzed by UV-Visible spectral analysis. Thermogravimetric-Differential thermal analyzer (TGA/DTA) and Differential Scanning calorimetric (DSC) analyzer has been carried out for the thermal stability of grown crystal. Mechanical stability of the crystal has been calculated by Vicker's microhardness measurement. Electrical conductivity of the crystal has been measured by dielectric studies. Second harmonic generation has been carried out by Kurtz-Perry powder technique in order to confirm it's enhance second harmonic generation efficiency.

\section{RESULTS AND DISCUSSIONS}

\subsection{FTIR Studies}

The FTIR study of INB crystal was carried out to confirm the existence of functional groups and their vibrational modes. The Fourier transform infrared spectrum of INB was notedfrom the region $400 \mathrm{~cm}^{-1}$ to $4000 \mathrm{~cm}^{-1}\left( \pm 4 \mathrm{~cm}^{-1}\right)$ with Perkin Elmer (model SPECTRUM RX1) Fourier transform infrared spectrophotometer using $\mathrm{KBr}$ pellet technique. The observed FTIR spectrum is shown in figure 2. The vibrational assignments of the INB crystal are noted intable1.

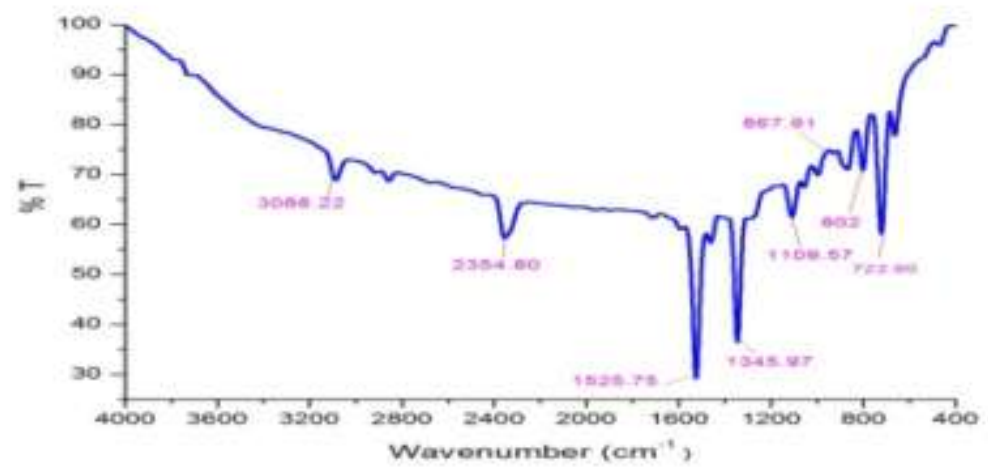

Fig2: FTIR Spectrum of INB crystals

Table 1. FT-IR Vibrational band assignments of INB crystal

\begin{tabular}{|c|c|}
\hline Wave number $\left(\mathbf{c m}^{-1}\right)$ & Vibration Assignments \\
\hline 722.90 & C-I stretching \\
\hline 867.91 & Asymmetric ring stretching \\
\hline 1109.57 & C-N stretching \\
\hline 1345.97 & Symmetric mode of the $\mathrm{NO}_{2}$ groups \\
\hline 1525.75 & C-C stretching in aromatic ring \\
\hline 2354.80 & C-H stretching \\
\hline 3088.22 & \\
\hline
\end{tabular}




\subsection{UV-Vis Studies}

The optical absorbance of INB crystal was recorded between the region 190-1100nm using LAMBDA-35 UV-Vis spectrophotometer, which includes near UV, visible and far IR regions. The UV-Vis absorbance spectra of the grown INB crystal is shown in figure 3.The strong absorption of INB crystal is occurred at $229 \mathrm{~nm}$. It may be due to yellow colour of crystal. There is no remarkable absorption in the range between $390 \mathrm{~nm}$ to $1100 \mathrm{~nm}$. The band gap energy of the crystal calculated is about $3.18 \mathrm{eV}$. The optical transparency of the crystal is identified in $390-1100 \mathrm{~nm}$ which makes this material can be right material for electro-optic modulators.

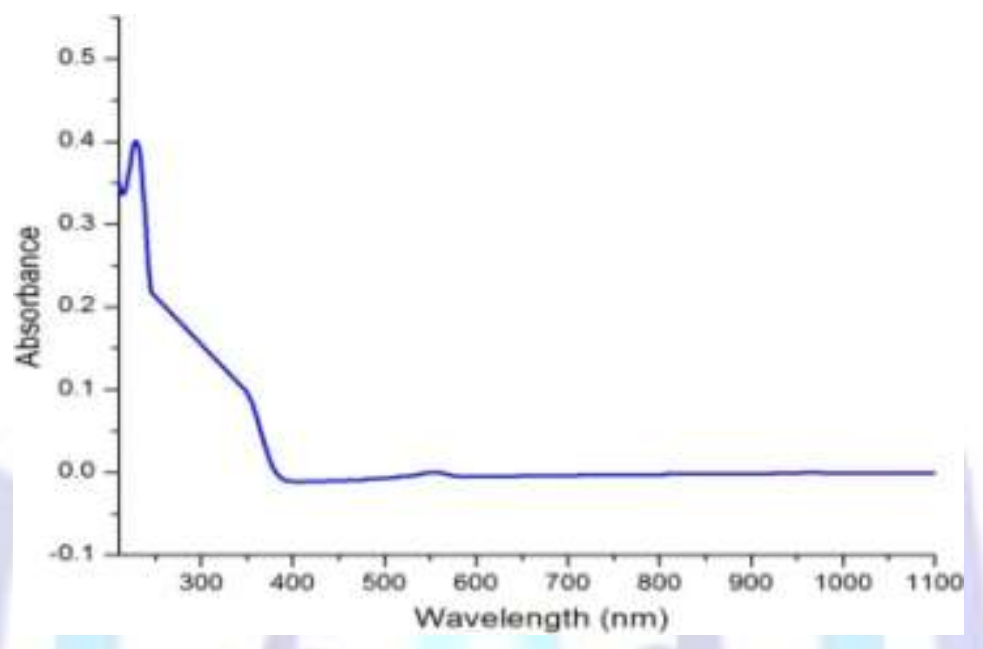

Fig 3: UV-Vis-absorbance Spectrum of INB crystals

\subsection{Mechanical Studies}

The mechanical strength of INB crystals were carried out using SHIMADZU (HMV-2T) Vicker's micro hardness tester fitted with a diamond indenter. The measurement was completed at different points on the crystal surface and the mean value was taken as the Hv for a given load.

The microhardness was calculated using the below relation,

$$
\mathrm{H}_{\mathrm{v}}=1.8544 \frac{P}{d^{2}}\left(\mathrm{~kg} / \mathrm{mm}^{2}\right)
$$

Where $P$ is the applied load and $d$ is the diagonal length of the indentation impression.

The calculated Vicker's hardness values for INB crystals as a function of load is shown in figure 3. The normal indentation size effect (ISE) involves decrease in hardness value with increasing load and the reverse indentation size effect (RISE) involves increase in hardness values with increasing load. Study of experiment data on crack lengths and indentation diagonals for various indentation loads suggests that the grown INB crystal origin of ISE is associated with the processes of formation of indentation cracks following the common concepts of fracture mechanics[5], there are many examples of normal occurrence of ISE in brittle materials [6].As grown INB crystals exhibit ISE, since indenter infiltrates the surface layers at all loads. By plotting log $P$ versus $\log d$, the value of work hardening coefficient $n$ is less than 1.6, that is 1.33 . It is evident from figure 5 which confirms that the crystal belongs to the category of moderately hard materials [7].

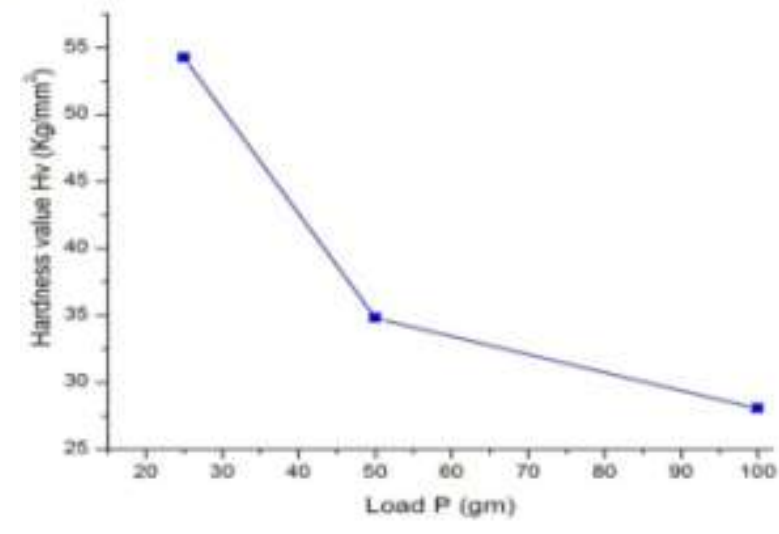

Fig4: Load versus Hardness value 


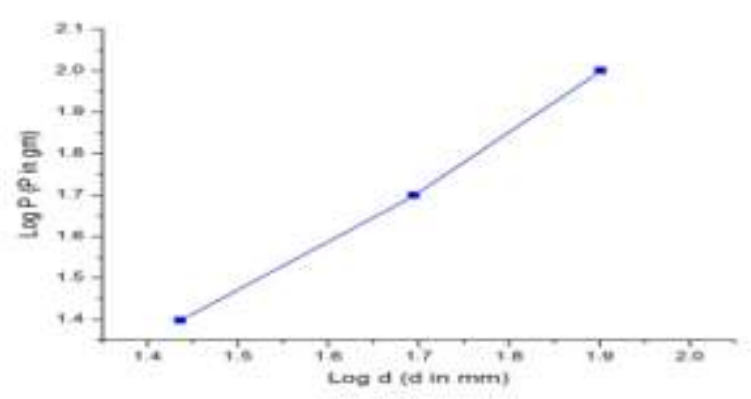

Fig 5: Log d versus Log P

\subsection{Thermal studies}

Tthermogravimetric and differential thermal analysis (TGA-DTA) of INB crystal were carried out by simultaneously in $\mathrm{N}_{2}$ gas atmosphere at a heating rate of $10^{\circ} \mathrm{C} /$ minute for a temperature range of $30^{\circ} \mathrm{C}-400^{\circ} \mathrm{C}$ using NETZSCH - STA $449 \mathrm{~F} 3$ JUPITER simultaneous thermal analyzer system. The recorded curves of TGA-DTA are shown in figure.6 It is obviously detected from the TGA spectrum that material has good thermal strength up to $148^{\circ} \mathrm{C}$. The major weight loss $(99 \%)$ of sample occurred from the temperature range $148^{\circ} \mathrm{C}$ to $282^{\circ} \mathrm{C}$. One important observation is that, there is no certain phase transition and this progresses the temperature range for the value of the crystal for NLO applications. Two endothermic peaks were observed from DTA curve whereas $36^{\circ} \mathrm{C}$ and $282^{\circ} \mathrm{C}$. The first endothermic peak at $36^{\circ} \mathrm{C}$ represents the melting point of the INB crystal and the second endothermic peak at $282^{\circ} \mathrm{C}$ represents around its boiling point.After melting, no particular exothermic or endothermic peaks were observed up to $282^{\circ} \mathrm{C}$ which shows that there is no degradation of the crystal above the melting point up to $282^{\circ} \mathrm{C}$. The sharpness of the endothermic peaks observed in DTA designates high degree of crystalline nature of the sample.The Differential Scanning Calorimetric analysis was carried out for sample of INB crystal by same NETZSCH - STA 449 F3 JUPITER simultaneous thermal analyzer system. A full examination of DSC curve is shown in figure.7. From the DSC curve, there are two major changes takes place when the sample is heating, first endothermic peak at $42^{\circ} \mathrm{C}$, second at $292^{\circ} \mathrm{C}$ temperature respectively. The first and second endothermic peaks correspond to melting point and boiling point of the sample. The exothermic dip point at $302^{\circ} \mathrm{C}$ corresponds to the decomposition of INB crystal into various gaseous products like $\mathrm{NO}_{2}, \mathrm{NO}$ etc. [8].

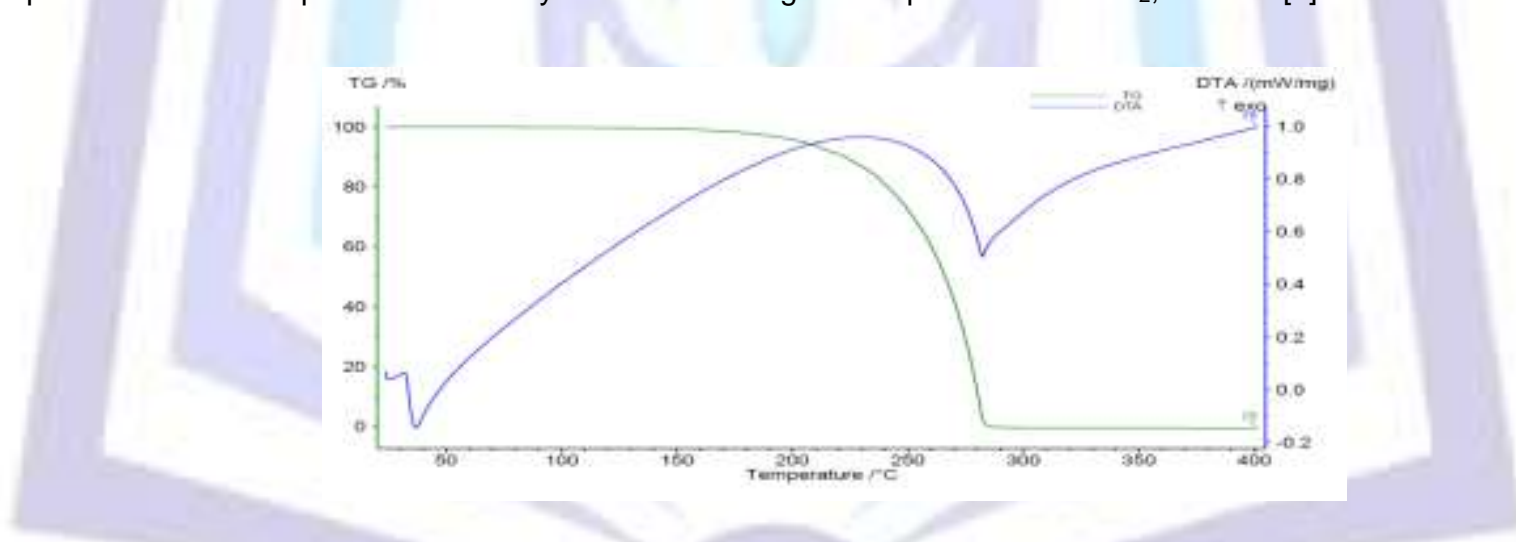

Fig 6: TG/DTA curve of INB crystals

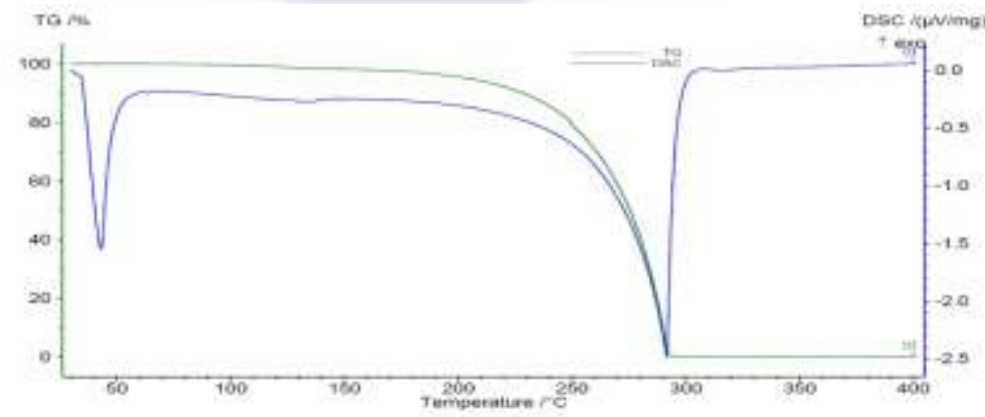

Fig 7: DSC curve of INB crystals 


\subsection{Powder XRD spectrum Studies}

Powder X-ray diffraction (PXRD) is a more powerful and useful tool to identify and characterize the crystal patterns. Most of the solid state studies now available in the PXRD patterns as a characteristic fingerprint of a particular crystalline phase. Powder X-ray diffraction (PXRD) data of INB crystal samples were collected using Rigaku mini Flex II X-ray diffractometer with CuKa $(1.54059 \AA)$ radiation at room temperature. The intensity of diffracted X-rays is continuously recorded as the sample and detector rotate through their respective angles. A peak in intensity occurs when the INB crystal has lattice planes with $d$-spacing suitable to diffract $X$-rays at that value of $\theta$. Although each peak consists of two distinct reflections $\left(\mathrm{Ka}_{1}\right.$ and $\left.\mathrm{Ka}_{2}\right)$ at lower values of $2 \theta$ the peak locations overlap with $\mathrm{Ka}_{2}$ seeming as a hump on the side of $\mathrm{Ka}_{1}$. Greater separation occurs at higher values of $\theta$. The differences in the peak amplitude can be recognized to the different sizes and orientation of the powdered grains. A diffraction pattern plots scattered intensity against the angle of the detector, $2 \theta$.The sharp and very intense XRD peaks were indexed and their confirmed that the material has the crystalline character. Hence Powder XRD can be used to determine the crystallinity by comparing the integrated intensity of the background form to that of the sharp peaks [9].

This crystal crystallizes in the non-centro symmetric, monoclinic space group $\mathrm{P} 1211$, the lattice parameters are reported as $a=5,977 \AA, b=5.224 \AA, c=11.972 \AA$. The lattice parameters obtained in powder X-ray diffraction well suited with the literature [4]. The powder diffraction spectrum for INB crystal is shown in figure 8.

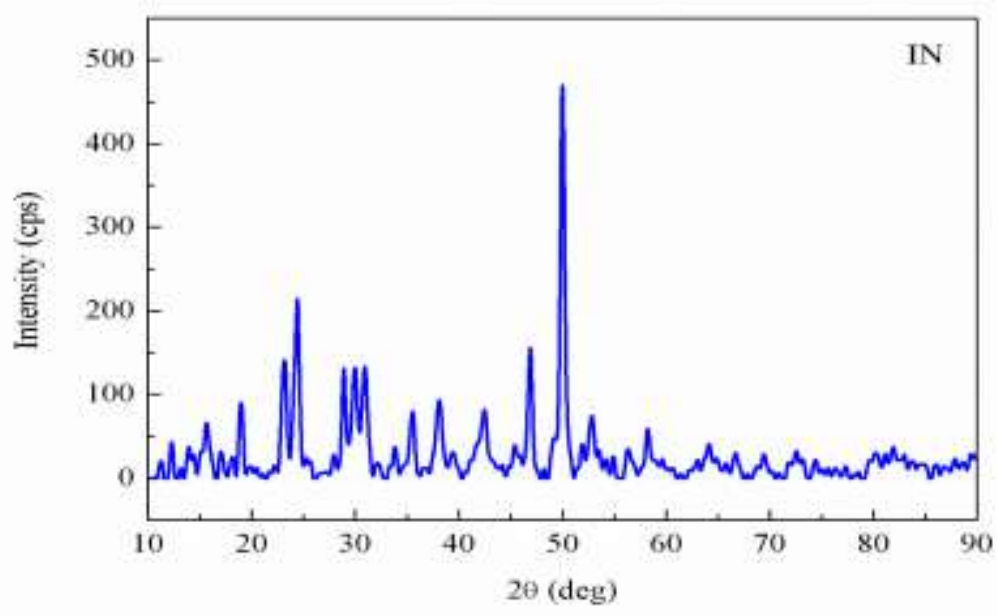

Fig 8: Powder XRD Spectrum of INB crystals

\subsection{NLO Studies}

Kurtz and Perry have industrialized an experimental technique for the evaluation of second harmonic generation (SHG) efficiency of material in powder form [10]. Many investigations have working with powder technique for the estimation of nonlinear optical material's SHG efficiency. The second harmonic generation efficiency of the grown INB crystal was carried out by Kurtz-Perry technique [11]. The well finely grained powder sample of INB crystal was tightly filled in very in thin glass tube. A Nd-YAG laser beam of $1064 \mathrm{~nm}$ wavelength, input power of $1.1 \mathrm{~mJ} /$ Pulse and $8 \mathrm{~ns}$ pulse width with $10 \mathrm{~Hz}$ pulse rate was made to fall normally on the sample, SHG is found by emission of green radiation from sample loaded thin glass tube.

The SHG efficiency of INB crystal was measured in powder form and compared to standard frequency doubling materials; KDP and Urea as in table.2.

Table 2. Comparison of SHG efficiency

\begin{tabular}{|c|c|c|}
\hline Compound & SHG efficiency relative to KDP & SHG efficiency relative to Urea \\
\hline 1 -iodo-3-nitrobenzene & 1.85 times & 0.93 times \\
\hline
\end{tabular}

\subsection{Dielectric studies}

The dielectric constant and the dielectric loss of INB crystal were studied at $30^{\circ} \mathrm{C}$ usingLCRZ digital meter in the frequency range $100 \mathrm{~Hz}$ to $100 \mathrm{KHz}$. Variation dielectric constant with frequency at room temperature is shown in figure 9 . The grown crystal has high dielectric constant at low frequencies and also there observed that decrement of dielectric constant with applied frequency increases. The high value of dielectric constant for applying low frequencies may be reason to the contribution of all the four polarizations and the low value of dielectric constant for applying high frequencies may be due to the loss of these polarizations gradually [12]. Figure 10 shows that the graph between log frequency and dielectric loss. 
It is observed that high value of dielectric loss for applying low frequencies and vice-versa. The low value of dielectric loss at high frequency for INB crystal indicates that the crystal has greater optical quality with minimum defects and this made for importance for NLO material [13]. A variation frequencyversus ac conductivity is shown in figure 11 which identifies the usual linear variation that is, increasing ac conductivity with increasing frequency as similar to Jonscher's power law [14].

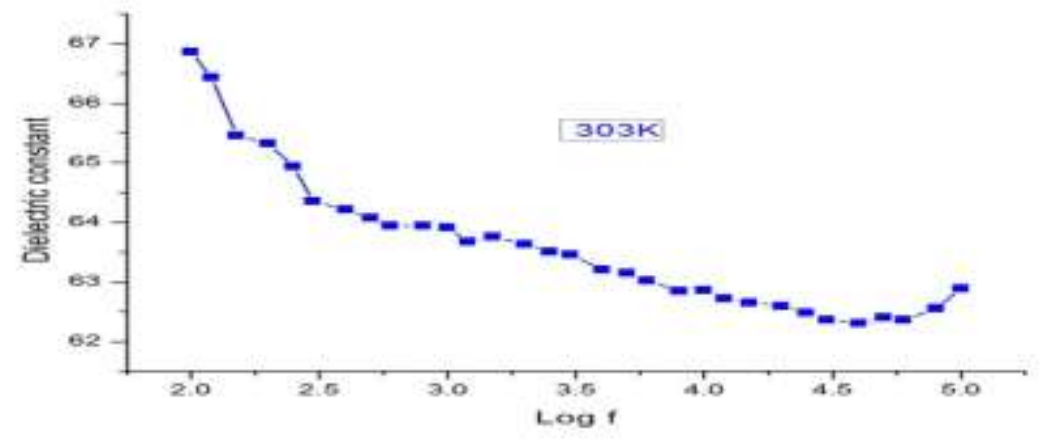

Fig 9: Variation of dielectric constant of INB crystal with varying frequency

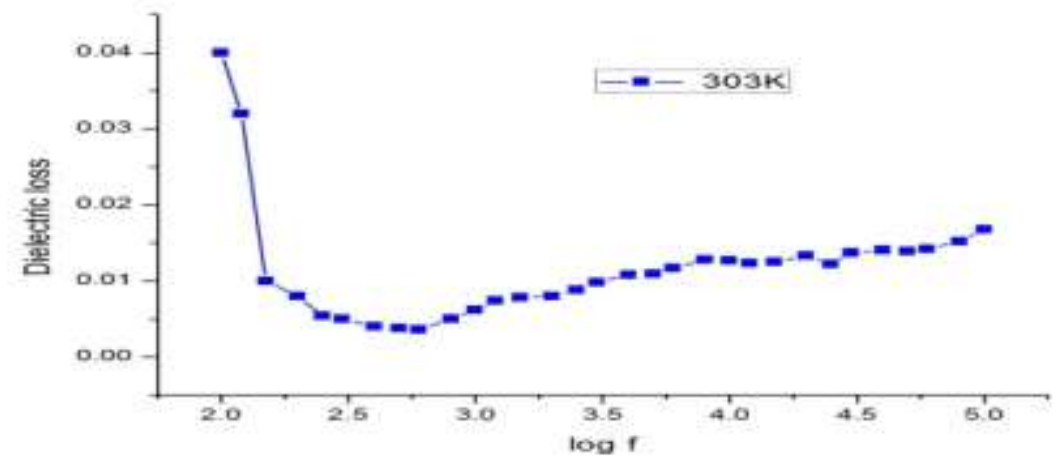

Fig 10: Variation of dielectric loss of INB crystal with varying frequency

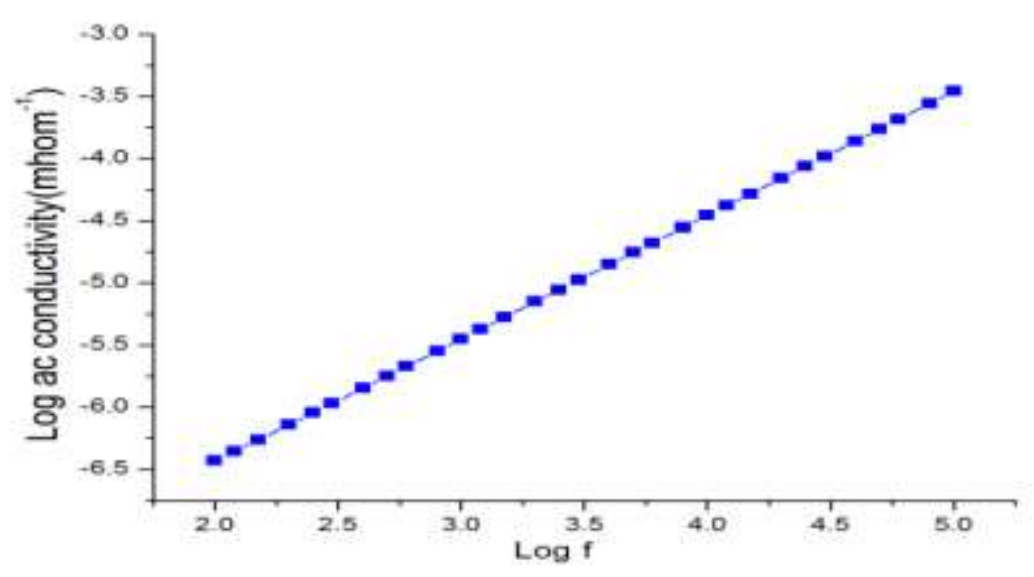

Fig 11: Variation of Logarithmic AC conductivity of INB crystal with varying frequency

\section{CONCLUSIONS}

Good quality 1-iodo-3-nitrobenzene crystals were grown by slow evaporation solution technique using ethanol as solvent. FTIR analyses bring out various functional group of INB. The grown crystal has high transmission window in the visible region $390-1100 \mathrm{~nm}$ and band gap energy value of INB is $3.18 \mathrm{eV}$. The mechanical stability of the INB crystal belongs to moderately hard material. Thermal stability of the compound up to $148^{\circ} \mathrm{C}$ has proved from TGA and DSC analysis. Powder X-ray diffraction analyzes confirms the cell parameters of INB crystal. The SHG frequency conversion of the grown crystal and its efficiency was 1.85 times that of KDP. The low value of dielectric loss at high frequency in INB crystals suggest that enhanced optical nature and low density defects which are of vital importance for NLO materials. 


\section{ACKNOWLEDGEMENTS}

Authors thanks to Dr. P.K. Das, IPC lab, IISC, Bangalore, Vincent sagayaraj, St. Joseph's college , Trichy and Selvi.G.Vidya, Research scholar, Biomaterials lab, Periyar university, Salem. One of the authors S.Vijayakumar thanks to Dr.K.Boopathy, Associate Professor \&Head of the Department of Physics, Government College of Engineering, Dharmapuri\&R.Vijayakumar, Assistant professor, P.S,V. Engineering College, Burgur, Krishnagiri for the valuable help and encouragement.

\section{REFERENCES}

1. Silinsh, E.A. 1980. Organic Molecular Crystals, Their Electronic States. Springer-Verlag Berlin Heidelberg, New York.

2. Evans, C. Beucher, M.B. Masse, R. Nicoud, J.F. "Nonlinearity Enhancement by solid-state Proton Transfer: A new strategy for the Design of Nonlinear Optical Materials",Chem.Mater. 10 (1998), 847-854.

3. Vijayakumar, S. Srinivasan,P. Dinagaran,S. Balaji, J. "Growth and Characterization of Organic Nonlinear Optical (NLO)

1,3-dinitrobenzene single crystals by vertical Bridgman method and its prospects as electro-optic modulators", International Journal of Applied Engineering Research. 10 (2015), 38055-38060.

4. Merz,K. “Secondary interactions in 1-iodo-3-nitrobenzene and 1-iodo-3,5-dinitrobenzene",ActaCrystallographica

SectionC.59 (2003), 65-67.

5. Sangwal,K. "On the reverse indentation size effect and microhardness measurement of solids",Materials Chemistry and Physics, 28 (February 2000), 145-152.

6. Sangwal, K. "Review: Indentation size effect, indentation cracks and microhardness measurement of brittle crystalline

solids - some basic concepts and trends",Cryst. Res. Technol. 44 (Oct. 2009), 1019-1037.

7. Onitsch,E.M, “Über die Mikrohärte der Metalle," Mikroskopie, 2(1947), 131-151.

8. Raziyeh, A.A. Saeid, A "Synthesis, Spectroscopy, Thermal Analysis, Magnetic Properties and Biological Activity Studies of $\mathrm{Cu}(\mathrm{II})$ and Co(II) Complexes with Schiff Base Dye Ligands", Molecules, 17 (2012), 6434-6448.

9. Chauhan, A. Chauhan, P. "Powder XRD Technique and its Applications in Science and Technology", Journal of Analytical \&Bioanalytical Techniques, 5(2014), 1-5.

10. Halim, H.M.A. "Second order non-linear optical properties of some organic compounds in powder”, Indian Journal of Engineering \& Materials Sciences, 11 (June 2004), 207-211.

11. Kurtz, S.K. Perry,T.T. "A powder technique for the evaluation of nonlinear optical materials". Journal of applied physics, 39(1968), 3798-3813.

12. Jothi, L.Vasuki, G. Ramesh Babu, R.Ramamurthi, K. "Synthesis, crystal growth and characterization of organic NLO material: 4-Bromo-4'-hydroxybenzylidene aniline”, Optik, 125 (2014), 2017-2021.

13. Kushwaha, S.K. Vijayan, N. Bhagavannarayana, G. "Growth by SR method and characterization of bis(thiourea)zinc(II) chloride single crystals",Materials letters, 62(2008), 3931-3933.

14. Joncher, A.K. "A new understanding of the dielectric relaxation of solids", Journal of materials science, 16 (1981) 2037-2060. 